\title{
Estimation of embrittlement during aging of AISI 316 stainless steel TIG welds
}

\author{
J NAYAK, K R UDUPA, K R HEBBAR* and H V S NAYAK \\ Department of Metallurgical and Materials Engineering, National Institute of Technology, Surathkal, \\ PO Srinivasnagar 575 025, India
}

MS received 10 August 2004

\begin{abstract}
Weldments of AISI grade 316 stainless steel, having a ferrite content of 4-6\% and a variety of nitrogen concentrations were prepared using a modified element implant technique. Charpy impact specimens prepared from these weldments were subjected to a variety of aging treatments. Impact toughness decreases with aging time at all aging temperatures. Nitrogen is found to be beneficial to toughness. An empirical relation connecting the aging temperature, aging time and nitrogen content with toughness has been developed which can be used to estimate the time for embrittlement.
\end{abstract}

Keywords. Stainless steel; TIG welds; aging; Charpy impact; lower shelf energy; embrittlement.

\section{Introduction}

Austenitic stainless steels have high ductility, low yield strength, high tensile strength, are easy to fabricate and have good corrosion resistance (Harvey 1979). In welding of these steels there are some difficulties including hot cracking (Hull 1967; David 1981; Gill et al 1989). To avoid this, the welds are designed to retain about $4-6 \%$ of ferrite. However, the ferrite is a metastable phase which can transform on aging thereby causing embrittlement of the weld.

Nitrogen additions to stainless steels have been found beneficial as it improves austenite stability and thereby reducing the nickel requirement. Nitrogen has also been found to enhance mechanical properties and corrosion resistance (Reed 1989).

The present work deals with the effect of nitrogen, aging temperature and aging time on the toughness of type 316 stainless steel TIG welds. The aging temperatures were selected keeping in mind the service conditions in the nuclear reactors where these steels are used. It was also intended to develop relation for predicting embrittlement as a function of all the above parameters.

\section{Experimental}

\subsection{Materials}

Nuclear grade AISI 316 stainless steel plates (composition as given in table 1) of dimensions $200 \times 100 \times 12 \mathrm{~mm}$ were obtained from IGCAR, Kalpakkam, India.

\footnotetext{
*Author for correspondence
}

Argon gas used for the experimental work was of commercial purity. The elemental chromium, required for obtaining the desired ferrite content, was in the form of granules of $99.99 \%$ purity.

\subsection{Equipment}

TIG welding equipment, TIG-400 (AC/DC), manufactured by Mogora Cosmic Pvt. Ltd., Pune, was used in this investigation. An auto torch movement set-up was fabricated and was mounted on a rigid working table. The movement of the torch was controlled by a motor through a belt and wheel arrangement to give a torch speed of $6 \mathrm{~cm} / \mathrm{min}$.

The ferrite content in the weld metal, expressed as a ferrite number, was determined using a ferrite tester known as Magne-gage.

Heat treatments were conducted in electrical resistance muffle furnaces with thyrister temperature controllers (accuracy of $\pm 1 \mathrm{~K}$ ).

The room temperature impact values of the welded and aged specimens were determined using Charpy impact tester of Russian make MK-30A with a capacity of $300 \mathrm{~J}$. The subzero impact values were obtained using Tinius Olsen instrumented impact testing machine of capacity $358 \mathrm{~J}$ available at IGCAR, Kalpakkam.

\subsection{Welding trials}

2.3a Modified element implant technique: Welds of the required composition were made using a novel element implant technique developed at IGCAR, Kalpakkam. In this, a TIG torch was held stationary and arc spot welds (stationary puddles) were made on centre line of the base 
metal plate, whilst adding chromium to achieve the desired ferrite content. The deposit was then homogenized by giving continuous weld passes, with a higher current (180-250 A) and higher shielding gas flow rate (12 1/min) than that employed in stationary puddle technique (50$80 \mathrm{~A} ; 6 \mathrm{l} / \mathrm{min}$, respectively). Two such passes were given. Calculated amount of nitrogen was introduced into the weld metal along with argon by means of a Y-connector during the final pass to achieve two more levels of nitrogen viz. 0.06 and $0.08 \mathrm{wt} \%$. This gives a weld penetration of about $6 \mathrm{~mm}$. In order to relieve the welding stresses and to increase the depth of penetration (from $6 \mathrm{~mm}$ to $8 \mathrm{~mm}$ ), the homogenized plates were annealed at $1073 \mathrm{~K}$ for $1 \mathrm{~h}$. A final weld pass was then made. The ferrite content of the weld regions was found to be within FN4FN6. The various stages of modified elemental implant technique are shown in figure 1.

2.3b Aging treatment: Specimens $(6 \times 6 \times 60 \mathrm{~mm})$ for Charpy impact tests were cut from the top layer of the plates in order to get the entire weld cross-section in these specimens. It is known (Abe et al 1987) that the sub-size samples yield results closely matching with those of standard size charpy samples under brittle fracture conditions. The samples were machined so that the weld zone lies at the centre occupying the entire cross-section of the specimen.

These specimens were then aged in furnaces maintained at different temperature levels viz. $673 \mathrm{~K}, 748 \mathrm{~K}$, and $773 \mathrm{~K}$ for periods of 1000,2000 and $5000 \mathrm{~h}$, respectively.

2.3c Charpy impact tests: The standard sub-size specimens of size $5 \times 5 \times 55 \mathrm{~mm}$ were cut from the $6 \times 6 \times 60 \mathrm{~mm}$ specimens after aging for required duration. V-notches (depth: $1 \mathrm{~mm}$; notch root radius: $0.25 \mathrm{~mm}$ ) were made at the centre of the weld in TS orientation as shown in figure 2.

Table 1. Chemical composition of AISI 316 stainless steel under investigation.

\begin{tabular}{lccccccc}
\hline Element & $\mathrm{C}$ & $\mathrm{Cr}$ & $\mathrm{Ni}$ & $\mathrm{S}$ & $\mathrm{Mo}$ & $\mathrm{Mn}$ & $\mathrm{N}$ \\
\hline Wt. \% & 0.067 & 16.2 & 12.1 & 0.04 & 3.0 & 1.2 & 0.03 \\
\hline
\end{tabular}

Charpy impact tests were carried out on as-welded as well as on welded and aged samples at different test temperatures ranging from $77 \mathrm{~K}$ to room temperature $(300 \mathrm{~K})$. The specimens were taken to test temperature and held for five min and were then subjected to Charpy impact test.

\section{Results}

The impact test results were used to generate impact energy vs test temperature plots. From these plots, the upper shelf energy (USE) and the lower shelf energy (LSE) were computed. The lower shelf was observed below $123 \mathrm{~K}$ in all tests performed.

The influence of parameters viz. aging temperature, aging time and nitrogen content, on the LSE are shown in figures 3 and 4. Though USE values were also affected by these parameters in a similar way, only LSE values are of relevance as the toughness of the material is decided by the level of impact energy shifting to lower values and LSE is always lower than USE.

\section{Discussion}

\subsection{Effect of aging}

Lower shelf energies (LSE) were found to decrease with aging time at all aging temperatures (figure 3). However, the extent of decrease is more as the aging temperature increases. $\delta$-Ferrite in austenitic stainless steel weld metals containing FN4-FN11 decomposes to $\alpha+\alpha^{\prime}$ at aging temperatures below $763 \mathrm{~K}$, but transforms to $\sigma$ at temperatures above $813 \mathrm{~K}$. At temperatures within that range, the two transformations occur simultaneously (Tavassoli et al 1984). Upon aging, the ferrite hardness increases and this hardening is accompanied by a noticeable increase in ductile-brittle transition temperature (DBTT) as indicated by Charpy test results. Ferrite decomposes spinodally into Fe-rich $\alpha$ and $\mathrm{Cr}$-rich $\alpha^{\prime}$ and, in addition, abundant precipitation of $\mathrm{Ni}$ and $\mathrm{Si}$ rich Gphase within ferrite and $\mathrm{M}_{23} \mathrm{C}_{6}$ occurs along the austenite-ferrite interface (Vitek et al 1991). The $\mathrm{R}(\mathrm{Fe}-\mathrm{Cr}-$ $\mathrm{Mo-Ni}$ ) phase may also precipitate within ferrite (Tavas-

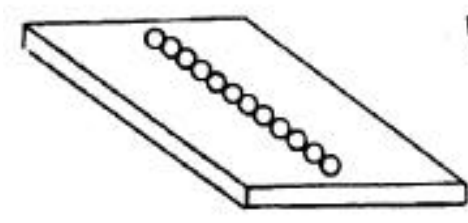

Stage I

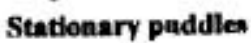

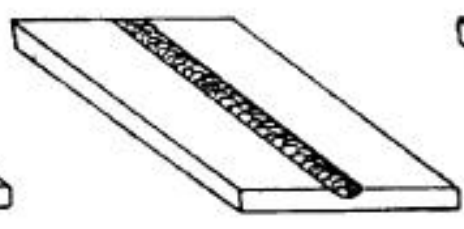

Stage II

After homogenization

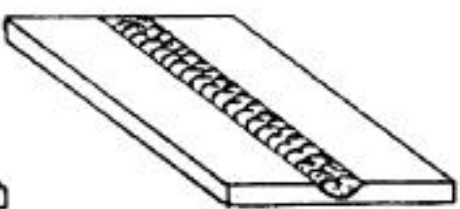

Stage III

After final pass

Figure 1. Various stages of weld simulation by elemental implant technique. 
soli et al 1984). The presence of Mo in 316SS welds enhances the kinetics of spinodal decomposition, and $\mathrm{C}$ and Mo atoms accelerate the precipitation of G-phase in ferrite matrix (Gill et al 1986; Chopra and Chung 1987). These effects are similar to the aging behaviour of cast stainless steel (Chung and Chopra 1988). Spinodal decomposition results in embrittlement of welds so far as the DBTT is raised. G-phase formation and carbide precipitation are associated with degradation in ductile fracture properties resulting in a drop in USE (Vitek et al 1991).

In the present investigation, the apparent activation energy, calculated from the Arrhenius plot (figure 5), is found to be $56 \mathrm{~kJ} / \mathrm{mol}$ and is in agreement with the reported value of activation energy for spinodal decomposition (Tavassoli et al 1984). This indicates that spinodal decomposition of ferrite is the main cause of embrittlement.

\subsection{Effect of nitrogen on LSE}

Lower shelf energy increases with increase in nitrogen content as seen in figure 4. This improvement in impact energy with increasing nitrogen content is generally seen at all aging temperatures and all aging times.

\subsection{Embrittlement}

For standard impact specimens $(10 \times 10 \times 55 \mathrm{~mm})$ made of ship steels the accepted embrittlement criterion is $20 \mathrm{~J}$ (Dieter 1988). For sub-size specimens $(5 \times 5 \times 55 \mathrm{~mm})$ as used in the present investigation (where the crosssectional area is $1 / 4$ that of standard charpy specimen), the embrittlement criterion could be taken as $1 / 4$ that of standard specimens, i.e. $5 \mathrm{~J}$, since for a perfectly brittle fracture, energy required for fracture is equal to the surface energy of newly created surface only. This is in agreement with the observation that the area normalization gives a better fit in the lower shelf region (Abe et al 1987). Fully cleavage fracture was observed in those specimens which showed LSE values $<5 \mathrm{~J}$ in the present investigation.

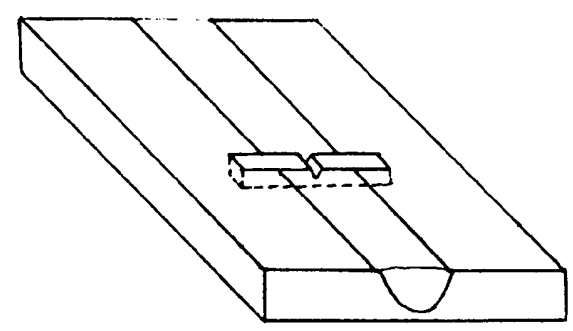

Figure 2. Schematic sketch showing the orientation of Charpy impact specimen (TS orientation) relative to the weld.
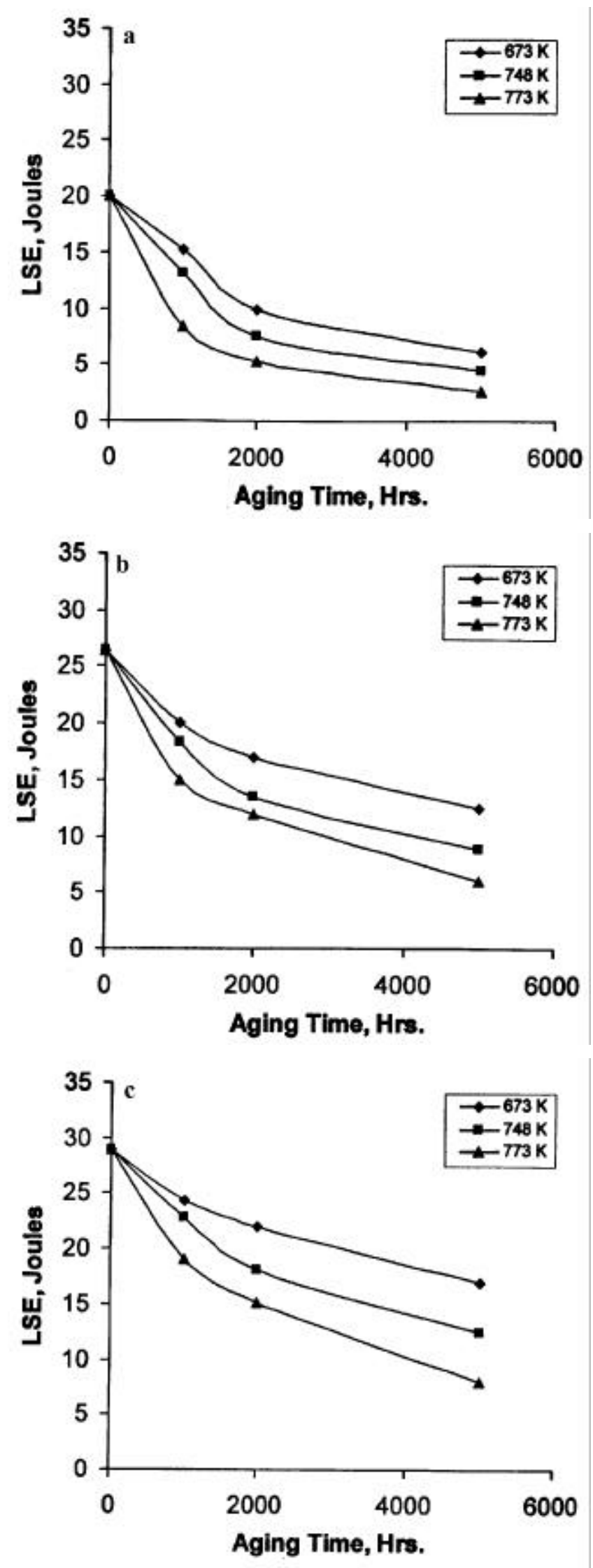

Figure 3. Effect of aging on lower shelf energy (LSE) of $316 \mathrm{SS}$ a. $0.03 \mathrm{~N}$, b. $0.06 \mathrm{~N}$ and c. $0.08 \mathrm{~N}$. 

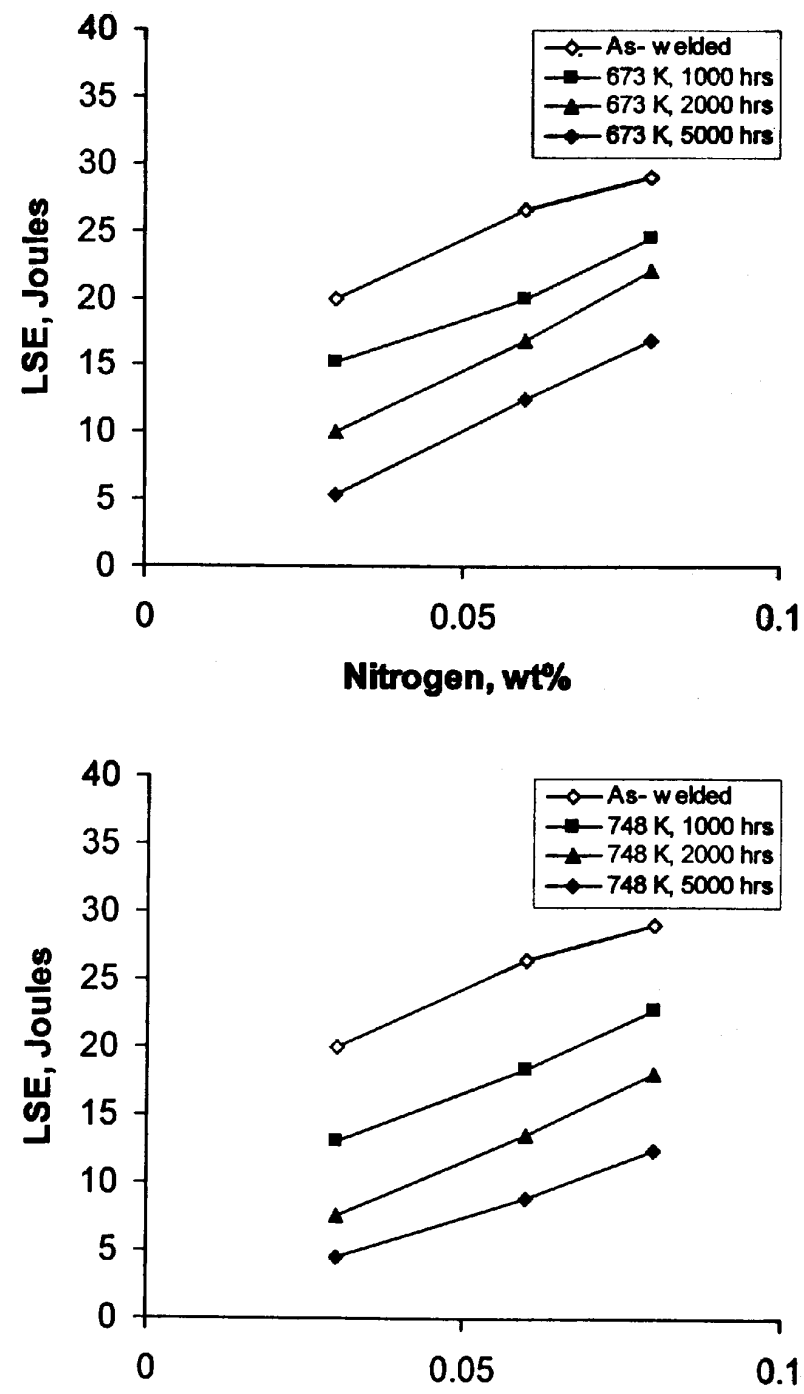

Nitrogen, wt\%

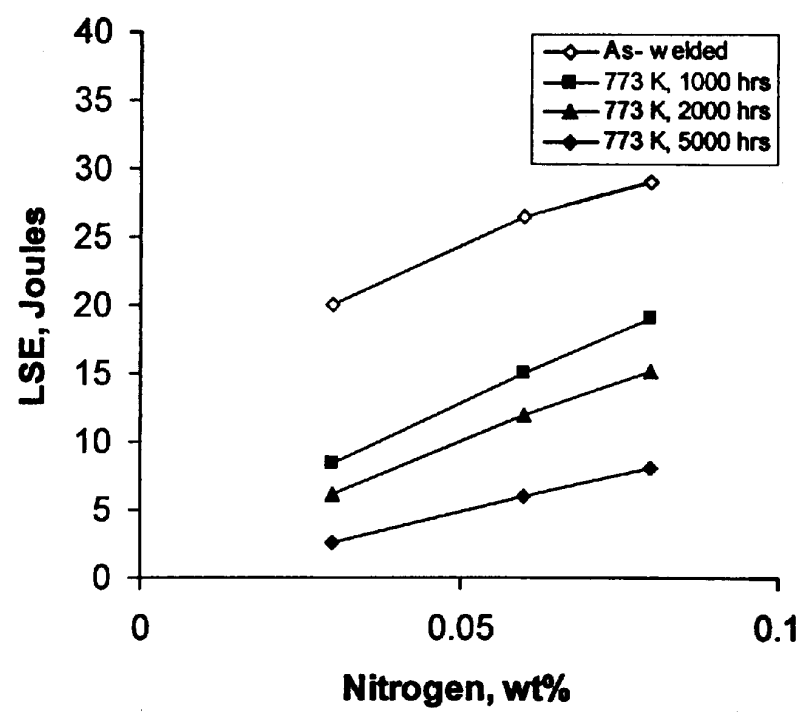

Figure 4. Effect of nitrogen on lower shelf energy (LSE) of as-welded and aged specimens.
Based on the above criterion for embrittlement, the least preferred aging conditions in the present work were identified and are as shown in table 2 .

It is clear from the above table that as the aging temperature and aging time increase, the resistance of steels to embrittlement decreases. Thus, the tendency for embrittlement is a strong function of the aging parameters such as aging temperature and aging time. Nitrogen addition is beneficial as the welds with higher nitrogen content show improved resistance to embrittlement.

Similar observations were made earlier in the case of AISI 304SS material also (Nayak et al 2004).

\subsection{Empirical relation}

It may be noted from table 2 that the least preferred conditions leading to embrittlement correspond to lowest nitrogen levels. As the nitrogen content increases the LSE values for the same aging conditions shift to higher values (figure 4). Thus, the tendency for embrittlement is a strong function of the aging parameters such as aging temperature, aging time and the nitrogen content of steels. Therefore, it is desirable to develop empirical relations connecting all these parameters to LSE. The experimental values were found to fall within a narrow band and the lower limit of the band was used to develop an empirical relation as given below:

$$
\begin{aligned}
\operatorname{LSE}(\text { in } \mathrm{J})= & 17.6 \times 10^{5}[(N / T \log t) \\
& \left.-32 \times 10^{-5} \times N\right]+1 \cdot 0,
\end{aligned}
$$

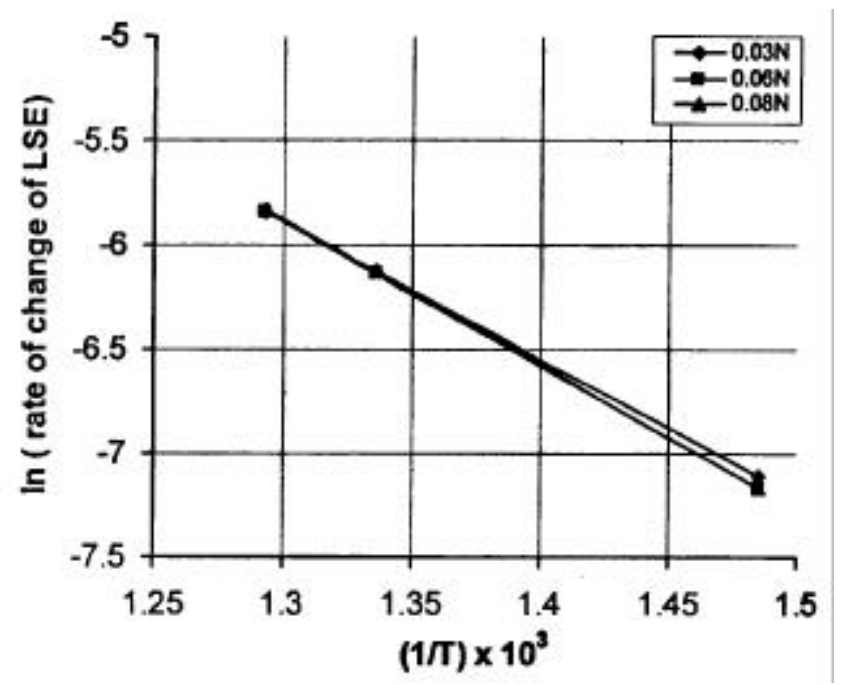

Figure 5. Arrhenius plot for the calculation of activation energy.

Table 2. Least preferred aging conditions causing embrittlement as identified in the present work.

\begin{tabular}{lcc} 
Material & Aging parameters & Impact energy (J) \\
\hline $316 \mathrm{SS}$ & $673 \mathrm{~K}, 5000 \mathrm{~h}$ & $5 \cdot 0$ \\
$(0.03 \mathrm{wt} \% \mathrm{~N})$ & $748 \mathrm{~K}, 5000 \mathrm{~h}$ & $4 \cdot 0$ \\
& $773 \mathrm{~K}, 2000 \mathrm{~h}$ & $5 \cdot 0$ \\
\hline
\end{tabular}




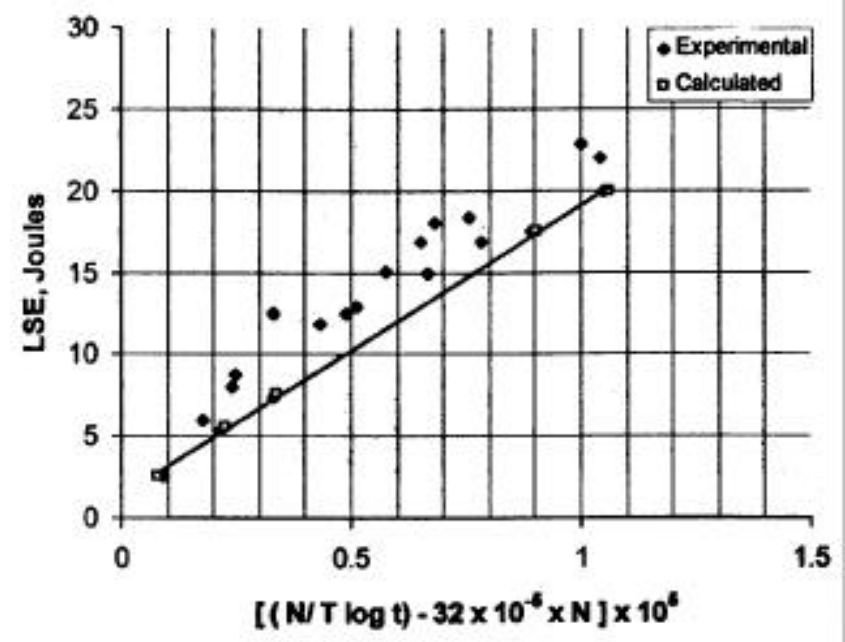

Figure 6. Line of empirical relation based on the lower limit of scatter band predicting embrittlement.

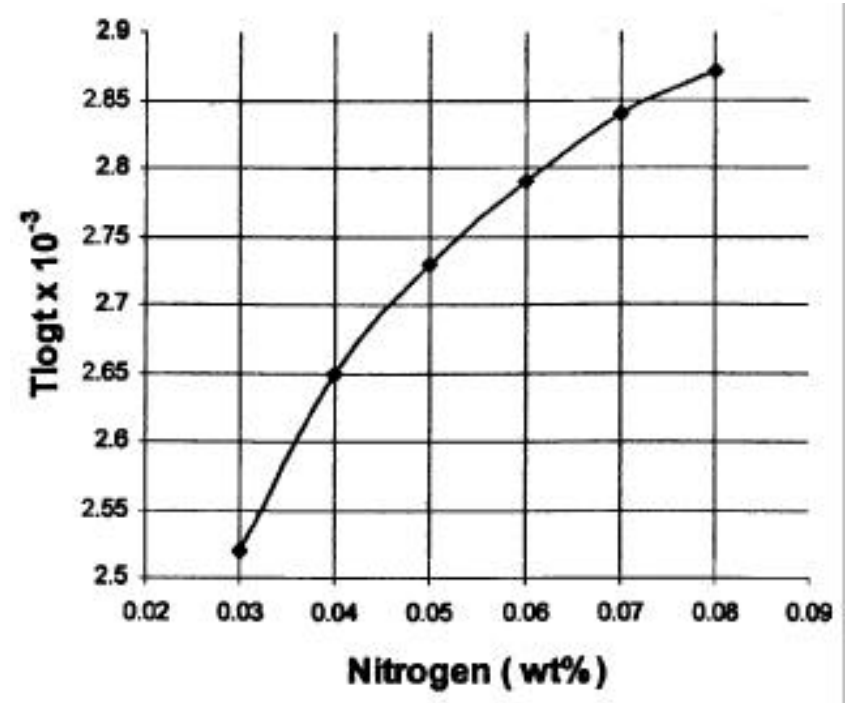

Figure 7. Combination of $N, T$ and $t$ to cause embrittlement (i.e. to reduce LSE to 5 Joules).

where $T$ is the aging temperature in Kelvin, $t$ the aging time in hours and $N$ the nitrogen content in wt \%. The values calculated using the above equation are in fairly good agreement with the experimental values as shown in figure 6 . However, it should be borne in mind that the above equation has limitations as regards to the range of values permitted for each parameter. The equation is valid for nitrogen levels starting from $0.03 \mathrm{wt} \%$ to the solubility limit in the steels concerned; and the aging temperatures between $673 \mathrm{~K}$ and $773 \mathrm{~K}$ (because, below $673 \mathrm{~K}$, aging practically has no significant effect on the impact energy due to extremely slow kinetics of precipitation, while above $773 \mathrm{~K}$, the embrittlement mechanisms may be altogether different).
The empirical relation can be used to predict the aging time required to cause embrittlement (to lower the LSE to $5 \mathrm{~J})$ for a given nitrogen content and aging temperature. Using LSE $=5 \mathrm{~J}$, a plot of $(T \log t)$ vs $N$ was generated as given in figure 7 from which the aging time for embrittlement for a given value of $N$ and $T$ can be easily estimated.

\section{Conclusions}

From the investigations carried out, the following conclusions were drawn:

(I) Lower shelf energy (LSE) is found to decrease with aging time at all temperatures.

(II) Nitrogen addition to the welds has beneficial effect as the resistance to embrittlement increases with increase in nitrogen content.

(III) Least preferred aging conditions for $316 \mathrm{SS}$ were found to be $673 \mathrm{~K}, 5000 \mathrm{~h}$ and $773 \mathrm{~K}, 2000 \mathrm{~h}$, for the lowest level of nitrogen (0.03 wt \%).

(IV) The empirical relation developed yields results that agree well with experimental values. The empirical relation developed can thus be used to predict the time for embrittlement at a given nitrogen level and aging temperature.

\section{Acknowledgements}

The authors acknowledge DAE, Govt. of India, for funding the project; IGCAR, Kalpakkam, for supplying the material and extending testing facilities; and Dr Placid Rodriguez, Dr T P S Gill and Dr V Shankar, IGCAR, Kalpakkam, for their valuable suggestions and help.

\section{References}

Abe F, Noda T, Araki H, Okada M, Narui M and Kayano H 1987 J. Nucl. Mater. 150292

Chopra O K and Chung H M 1987 Quarterly Progress Report NUREC/CR-4744 245

Chung H M and Chopra O K 1988 TMS-AIME 359

David S A 1981 Welding J. $6063 \mathrm{~S}$

Dieter G E 1988 Mechanical metallurgy (Singapore: McGraw Hill) SI Metric Edition

Gill T P S, Vijayalakshmi M, Gnanamoorthy J B and Padmanabhan K A 1986 Welding J. 65 122S

Gill T P S, Vijayalakshmi M, Rodriguez P and Padmanabhan K A 1989 Met. Trans. 201115

Harvey P D 1979 Engineering properties of steel (Metals Park, Ohio: Amer. Soc. for Metals) 9th ed.

Hull F C 1967 Welding J. 46 399S

Nayak J, Udupa K R, Hebbar K R and Nayak H V S 2004 Mater. Sci. and Technol. (communicated)

Reed R P 1989 J. Metals 316

Tavassoli A A, Bisson A and Soulat P 1984 Metal Sci. 18345

Vitek J M, David S A, Alexander D J, Keiser J R and Nanstad R K 1991 Acta Met. Mater. 39503 